\title{
PENGARUH ATTITUDE HOMOPHILY, SOCIAL ATTRACTIVENESS, SELF- DISCLOSURE, ENDORSER CREDIBILITY, DAN PARASOCIAL INTERACTION TERHADAP PURCHASE INTENTION
}

\author{
Fresha Kharisma \\ Universitas Airlangga \\ freshakharisma@gmail.com \\ Masmira Kurniawati \\ Universitas Airlangga \\ masmira.kurniawati@gmail.com
}

\begin{abstract}
The increase in internet users encourages endorsers to market a product to shift to online media such as Youtube. The use of the online media Youtube by endorsers creates a unique attraction and can encourage consumers to make purchases. The purpose of this study is to determine the factors that need to be considered by marketers in marketing their products so that they can achieve a high level of consumer purchase intention. This research uses a quantitative survey method by distributing 210 questionnaires to Youtube viewers who have seen Atta Halilintar and know AHHA fashion products. Testing using structural equation models (SEM) shows the factors influencing consumer purchase intentions. The results show attitude homophily has a significant effect on endorser credibility. Attitude homophily, social attractiveness, and self-disclosure significantly affect parasocial interaction. Relationship with endorser credibility also has a significant impact on purchase intention. Social relationships have a significant effect on parasocial interactions. Interaction has a significant effect on Atta Halilintar's audience's purchase intention. This study implies that the endorsers who have the personality, credibility, and parasocial interactions that the audience likes will influence their purchase intention.
\end{abstract}

Keywords: attitude homophily; social attractiveness; self-disclosure; endorser credibility; parasocial interaction.

\section{PENDAHULUAN}

Pertumbuhan jumlah pengguna internet di indonesia selalu meningkat dari tahun ke tahun. Terdapat 112,6 juta pengguna internet pada 2017, yang menunjukkan peningkatan pada tahun 2019 sebesar 150,0 juta pada 2020 menjadi 175,0 juta (emarketer.com, 2019). Meningkatnya pengguna internet serta media sosial membuat pemasar tidak hanya memasarkan produknya melalui media tradisional seperti televisi serta koran, namun mulai beralih ke media online. Pertumbuhan internet yang semakin pesat ini juga diikuti oleh perkembangan media sosial yang meningkat, di Indonesia mayoritas menggunakan platform media sosial seperti Instagram, Youtube, Facebook dan Whatsapp. Persentase pengguna media sosial pada tahun 2020 terbesar adalah Youtube dengan jumlah persentase sebesar 88\% (WeAreSocial \& Hootsuite, 2020). Youtube merupakan media platform online paling banyak digunakan oleh masyarakat Indonesia, salah satu alasan yang mendasari selebriti dan endorser membuat Youtube adalah agar membuat diri mereka tetap eksis dan bisa lebih dekat dengan penontonya dengan cara penonton dapat menulis komentar di media Youtube (Hadijah, 2019).

Atta Halilintar merupakan endorser dan kreator Youtube yang memiliki subscribers dan viewers terbanyak di Indonesia dengan jumlah penonton 2,50 miliar dan pelanggan 23,8 juta (kompas.com, 2020). Menurut Samat et al. (2015), endorser adalah adalah pendukung iklan atau disebut dengan bintang iklan yang mendukung produk yang diiklankan dengan cara menyampaikan sebuah pesan dengan memperagakan suatu produk atau jasa. Atta Halilintar memiliki produk fashion dengan nama merek AHHA Ada beberapa kategori produk AHHA (kids, man\&woman, accessories, crewneck, 
hoodie, T-shirt, topi), Produk AHHA dapat dibeli melalui online web attahalilintarhabit.com atau ke store AHHA Jakarta, Bandung, Surabaya dan Bali serta melalui beberapa marketplace. Banyaknya saluran penjualan menunjukkan bahwa produk AHHA cukup diminati oleh masyarakat (Maharani, 2019). Hal ini menunjukan bahwa peminat konsumen terhadap produk AHHA tinggi. Dalam penelitian ini tidak melihat tentang penilaian produk akan tetapi untuk melihat faktor persuasi dari endorser akankah memberikan dampak pengaruh yang tinggi ke penonton untuk melakukan niat beli.

Tujuan dari artikel ini adalah untuk mengetahui faktor apa saja yang yang perlu diperhatikan oleh pemasar dalam memasarkan produknya agar tingkat purchase intention seseorang menjadi tinggi. Hal tersebut meningkatkan pemahaman isyarat persuasi yang berkaitan dengan endorser di media sosial yang berfokus pada media sosial Youtube. Artikel ini fokus pada faktor-faktor persuasi yang berhubungan dengan produk fashion yang dibawakan oleh endorser yakni bagaimana attitude homophily, social atractiveness, Youtube self disclosure, endorser credibility, parasocial interaction dan memengaruhi purchase intention. Adapun pemilihan Atta Halilintar sebagai objek dalam penelitian ini dikarenakan Atta merupakan salah satu sosok endorser di Indonesia yang sangat popular pada saat ini dan memiliki banyak jumlah penonton Atta sendiri juga memiliki produk yang juga dipromosikan melalui akun channel Youtube Atta itu sendiri (Maharani, 2019).

\section{KAJIAN PUSTAKA DAN PENGEMBANGAN HIPOTESIS}

\section{Attitude Homophily}

Kesamaan antara individu yang berinteraksi dalam hal cara bersikap disebut sikap homofili (Sokolova dan Kefi, 2019). Attitude homophily menurut Eyal dan Rubin (2010) merupakan suatu persepsi dari penonton dalam melihat kesamaan dari seorang endorser yang dikagumi dengan dirinya, didasarkan dari sikap yang sama seperti halnya sikap menghargai, menghormati dan bertanggung jawab.

Berdasarkan penelitian Sokolova dan Kefi (2019), attitude homophily sebagai faktor penentu credibility karena mengacu pada persepsi kesamaan antara endorser dan pengikut yang membuat informasi yang disampaikan oleh endorser credibility kuat di mata pengikutnya. Orang yang serupa dalam segi penampilan atau pemikiran dapat menginspirasi kepercayaan informasi yang diberikan karena solusi yang diusulkan juga dapat bekerja untuk audiens karena kesamaan antara pembicara dan anggota audiens (Levine dan Valle 1975).

H1: Attitude homophily berpengaruh positif terhadap endorser credibility.

Attitude homophily juga didefinisikan sebagai tingkat di mana orang cenderung merasa terikat dengan orang lain yang serupa dengan dirinya (Sokolova dan Kefi, 2019), Sedangkan menurut Kurtin, Kate Szer dan O'Brien (2018), parasocial interaction adalah adanya hubungan satu arah di mana penonton dapat seolah-olah memiliki hubungan dengan figur media, tapi hubungan tersebut bersifat satu arah.

Ketika seseorang merasa memiliki kesamaan dengan orang lain (Attitude homophily) yang tinggi maka seseorang itu akan merasa memiliki hubungan yang erat dengan seorang figur dan merasa memiliki hubungan dengan figur tersebut. Oleh karena itu akan mengembangkan hubungan dengan orang yang mereka sukai dengan cara berkomunikasi di media sosial.

H2: Attitude homophily berpengaruh positif terhadap parasocial interaction. 
Fresha Kharisma \& Masmira Kurniawati. Pengaruh Attitude Homophily, Social Attractiveness, Self-Disclosure, Endorser Credibility, dan Parasocial Interaction terhadap Purchase Intention

\section{Social Attractiveness}

Sokolova dan Kefi (2019) mendefinisikan social attractiveness sebagai kemampuan yang dimiliki seseorang yang menimbulkan ketertarikan orang yang melihatnya untuk berteman. Parasocial interaction adalah adanya hubungan satu arah di mana penonton dapat seolah-olah memiliki hubungan dengan figur media, tapi hubungan tersebut bersifat satu arah.

Endorser yang komunikatif dan responsif di media sosial menciptakan ilusi kepada pengguna media bahwa mereka berperilaku seolah-olah mereka berada di lingkaran rekan-rekan mereka sehingga dianggap orang menarik secara sosial (Liu, Liu, dan Zhang, 2019). Ketika seseorang yang memiliki Social attractiveness yang tinggi maka akan memengaruhi orang lain untuk melakukan parasocial interaction (Liu et al., 2019).

H3: Social attractiveness berpengaruh positif terhadap parasocial interaction.

\section{Self-Disclosure}

Menurut Masaviru (2016) menyatakan bahwa self-disclosure adalah sebuah proses membeberkan informasi tentang diri sendiri kepada orang lain. Self-disclosure adalah tindakan mengungkapkan informasi terkait diri kepada orang lain yang dapat memperkuat kedekatan di antara individu (Chen et al., 2016).

Menurut Kurtin, Szer, \& O’Brien (2018), parasocial interaction adalah adanya hubungan satu arah di mana penonton dapat seolah-olah memiliki hubungan dengan figur media, tapi hubungan tersebut bersifat satu arah. Endorser berbagi pengalaman suatu produk dan menceritakan kehidupan mereka di media sosial ataupun Youtube dan penonton berinteraksi dengan menulis komentar serta membayangkan bahwa mereka berbagi persahabatan nyata di media sosial Youtube.

H4: Self-disclosure berpengaruh positif terhadap parasocial interaction.

\section{Endorser Credibility}

Endorser credibility menurut Samat, Hashim, dan Raja Yusof (2015) adalah sejauh mana endorser dianggap dapat dipercaya. Menurut Goldsmith et al. (2000), kredibilitas endorser adalah level kepercayaan konsumen terhadap suatu pemberian informasi dari seorang endorser.

Endorser credibility juga didefinisikan sebagai sejauh mana endorser dipandang menarik, memiliki keahlian dan dapat dipercaya. Semakin menarik, ahli, dan dapat dipercaya seorang endorser maka dapat memengaruhi purchase intention konsumen (Sokolova dan Kefi, 2019). Sedangkan Definisi purchase intention adalah kecenderungan dan hasrat yang secara kuat mendorong individu untuk membeli suatu produk (Lin dan Ching Yuh, 2010). Ketika endorser dianggap semakin menarik, ahli, dan dapat dipercaya maka akan memberikan dampak yang signifikan terhadap niat beli konsumen (Ridha \& As'ad, 2018).

H5: Endorser credibility berpengaruh positif terhadap purchase intention.

\section{Parasocial Interaction}

Parasocial interaction adalah hubungan satu arah di mana penonton dapat seolah-olah memiliki hubungan dengan figur media, tapi hubungan tersebut bersifat satu arah (Kurtin, Kate Szer dan O’Brien 2018). Menurut Horton dan Wohl (1956), definisi interaksi parasosial adalah suatu reaksi 
penonton dengan seorang figur yang terjadi saat kedua belah pihak melakukan interaksi melalui suatu paparan media seperti televisi, radio dan teater, penonton mempersepsikan figur idola mereka adalah teman bercengrama yang sangat dekat. Sokolova dan Kefi (2019) menyatakan bahwa seorang penonton yang memiliki parasocial interaction dengan figur idola akan merasa ada kedekatan sehingga membuat penonton akan membeli produk karena kedekatan yang dirasakan penonton.

H6: Parasocial interaction berpengaruh positif terhadap purchase intention.

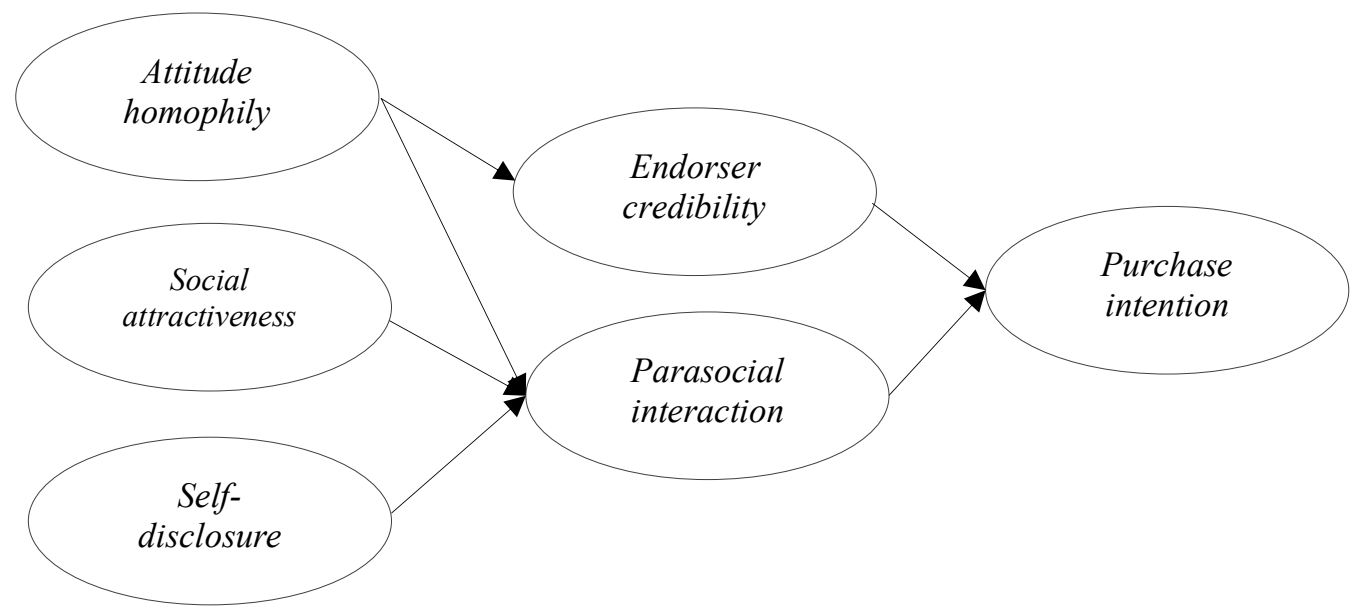

Gambar 1. MODEL PENELITIAN

\section{METODE PENELITIAN}

Penelitian ini menggunakan metode kuatitatif. Data dikumpulkan menggunakan kuisioner dengan skala Likert dari Sangat Tidak Setuju hingga Sangat Setuju. Populasi penelitian ini adalah penonton vlog dari Atta Halilintar di situs YouTube. Teknik sampling yang digunakan adalah judgmental sampling dengan jumlah 210 sampel yang menjawab 21 indikator dalam kuisioner. Untuk pengujian hipotesis, penelitian ini menggunakan teknik analisis Struktural Equation Model (SEM) yang diolah dengan bantuan program AMOS. Model kausal AMOS menunjukkan pengukuran dan masalah yang struktural dan digunakan untuk menganalisis dan menguji model hipotesis.

\section{HASIL DAN PEMBAHASAN}

\section{Uji Validitas dan Reliabitas}

Berdasarkan hasil penelitian diperoleh hasil uji validitas dan konvergen. Berdasarkan Tabel 1, terdapat 21 item yang memiliki nilai loading factor $\geq 0,50$ dan seluruh variable memiliki nilai construct reliability $>0,70$. Sehingga, seluruh variabel dalam penelitian ini memiliki validitas dan reliabilitas baik.

\section{Uji Kesesuaian Model}

Hasil pengujian kesesuaian model dalam penelitian dapat dilihat pada Tabel 2 dan dapat diketahui bahwa sebelas kriteria yang digunakan untuk menilai layak atau tidaknya suatu model telah terpenuhi dan hanya tiga yang tidak terpenuhi. Pada tahap analisis kesesuaian terhadap full structural model, model penelitian ini dilakukan evaluasi dengan menggunakan goodness of fit index. Hasil perhitungan nilai-nilai indeks pada goodness of fit yang dihasilkan oleh model penelitian ini ditunjukkan pada Tabel 2. Hasil pengujian goodness of fit menunjukkan bahwa model SEM pada penelitian ini sudah 
Fresha Kharisma \& Masmira Kurniawati. Pengaruh Attitude Homophily, Social Attractiveness, Self-Disclosure, Endorser Credibility, dan Parasocial Interaction terhadap Purchase Intention

baik dan dapat diterima. Dengan demikian, analisis uji hipotesis lebih lanjut dapat dilakukan. Berdasarkan uji hipotesis dengan tingkat alpha 5\%. Hasil pengujian semua hipotesis signifikan atau dengan kata lain, seluruh hipotesis terbukti dalam penelitian ini.

Tabel 1. HASIL UJI VALIDITAS DAN RELIABILITAS

\begin{tabular}{|c|c|c|c|c|c|}
\hline \multirow{2}{*}{$\begin{array}{l}\text { Variabel } \\
\text { Indikator }\end{array}$} & \multicolumn{3}{|c|}{ Uji Validitas } & \multicolumn{2}{|c|}{ Uji Reliabilitas } \\
\hline & Loading Factor & Probability & Keterangan & Construct Reliability & Keterangan \\
\hline Y24 & 0.823 & $* * *$ & Valid & & \\
\hline Y23 & 0.745 & $* * *$ & Valid & 0841272 & Reliahel \\
\hline Y22 & 0.796 & $* * *$ & Valid & $0.8412 / 2$ & Rellabel \\
\hline Y21 & 0.649 & $* * *$ & Valid & & \\
\hline $\mathrm{X} 23$ & 0.778 & $* * *$ & Valid & & \\
\hline $\mathrm{X} 22$ & 0.581 & $* * *$ & Valid & 0.736063 & Reliabel \\
\hline $\mathrm{X} 21$ & 0.444 & $* * *$ & Valid & & \\
\hline X33 & 0.778 & $* * *$ & Valid & & \\
\hline X32 & 0.886 & $* * *$ & Valid & 0.817645 & Reliabel \\
\hline X31 & 0.647 & $* * *$ & Valid & & \\
\hline $\mathrm{X} 13$ & 0.732 & $* * *$ & Valid & & \\
\hline $\mathrm{X} 12$ & 0.712 & $* * *$ & Valid & 0.750427 & Reliabel \\
\hline $\mathrm{X} 11$ & 0.678 & $* * *$ & Valid & & \\
\hline Y11 & 0.753 & $* * *$ & Valid & & \\
\hline Y12 & 0.731 & $* * *$ & Valid & 0.851878 & Reliabel \\
\hline Y13 & 0.581 & $* * *$ & Valid & & \\
\hline Y35 & 0.798 & $* * *$ & Valid & & \\
\hline Y34 & 0.808 & $* * *$ & Valid & & \\
\hline Y33 & 0.847 & $* * *$ & Valid & 0.93311 & Reliabel \\
\hline Y32 & 0.859 & $* * *$ & Valid & & \\
\hline Y31 & 0.818 & $* * *$ & Valid & & \\
\hline
\end{tabular}

Sumber: Data diolah (2020)

\section{Pembahasan}

Berdasarkan pengujian $\mathrm{H} 1$, variabel attitude homophily berpengaruh terhadap variabel endorser credibility. Pada penelitian ini dijelaskan bahwa relevansi kesamaan sikap yang tinggi akan memengaruhi tingkat endorser credibility. Kebanyakan orang meyukai berinteraksi dengan orang lain yang mirip dengannya. Seorang individu dapat menyerap paparan informasi dari sumber-sumber yang dianggap sangat kredibel, menarik, dan homofil karena sumber-sumber tersebut menyediakan penguatan yang cukup dan mendukung (Cocker, Mardon, \&Daunt, 2021).

H2 menyatakan bahwa variabel attitude homophily mempunyai pengaruh terhadap parasocial interaction. Pada penelitian ini dijelaskan bahwa semakin adanya kesamaan sikap antara endorser di Youtube dengan penonton, semakin tinggi tingkat parasocial interaction seseorang. Hasil dari penelitian ini menunjukan bahwa tingkat attitude homophily berpengaruh terhadap parasocial interaction. Berdasarkan penelitian sebelumnya yaitu Lee dan Watkins (2016), attitude homophily juga dianggap sebagai penentu parasocial interaction di media sosial.

Berdasarkan pengujian Hipotesis H3 menyatakan bahwa variabel social attractiveness mempunyai pengaruh terhadap parasocial interaction. Pengaruh tersebut terjadi ketika endorser memiliki social attractiveness yang tinggi maka membuat penonton ingin berinteraksi dengan endorser tersebut. Endorser yang komunikatif dan responsif di media sosial menciptakan ilusi kepada pengguna media bahwa mereka berperilaku seolah-olah mereka berada di lingkaran rekan-rekan mereka sehingga 
dianggap orang menarik secara sosial (Liu, Liu, dan Zhang, 2019).

Tabel 2. UJI KRITERIA GOODNESS OF FIT

\begin{tabular}{|c|c|c|c|}
\hline Kriteria & Cut off Value & Hasil Pengujian & Keterangan \\
\hline$X^{2}$ chi square & $\begin{array}{c}\text { Diharapkan lebih kecil dari } \\
212,3\end{array}$ & 116,337 & Fit \\
\hline $\begin{array}{l}\text { Significance } \\
\text { Probability }\end{array}$ & $\geq 0,05$ & 1,738 & Fit \\
\hline GFI & $\geq 0,9$ & 0,956 & Fit \\
\hline AGFI & $\geq 0,9$ & 0,815 & Marjinal \\
\hline TLI & $\geq 0,95$ & 0,583 & Tidak fit \\
\hline CFI & $\geq 0,95$ & 0,643 & Tidak fit \\
\hline RMSEA & Antara $0,03-0,08$ & 0,06 & Fit \\
\hline CMIN/DF & $\leq 2,0$ & 1,757 & Fit \\
\hline AIC & $\begin{array}{l}\text { Lebih Kecil dari Independent } \\
\text { Model }(633,82)\end{array}$ & 418,33 & Fit \\
\hline CAIC & $\begin{array}{l}\text { Lebih Kecil dari Independent } \\
\text { Model }(725,11)\end{array}$ & 640,03 & Fit \\
\hline $\mathrm{BCC}$ & $\begin{array}{l}\text { Lebih Kecil dari Independent } \\
\text { Model }(638,76)\end{array}$ & 430,33 & Fit \\
\hline BIC & $\begin{array}{l}\text { Lebih Kecil dari Independent } \\
\text { Model }(704,11)\end{array}$ & 589,03 & Fit \\
\hline ECVI & $\begin{array}{l}\text { Lebih Kecil dari Independent } \\
\text { Model }(3,0)\end{array}$ & 2,0 & Fit \\
\hline MECVI & $\begin{array}{l}\text { Lebih Kecil dari Independent } \\
\text { Model }(3,0)\end{array}$ & 2,05 & Fit \\
\hline
\end{tabular}

Sumber: Data diolah (2020)

Tabel 3. HASIL REGRESSION WEIGHT

\begin{tabular}{|c|c|c|c|c|c|c|}
\hline \multirow{2}{*}{$\begin{array}{c}\text { Hipotesis } \\
\mathrm{H} 1\end{array}$} & \multicolumn{3}{|c|}{ Pengaruh } & \multirow{2}{*}{$\begin{array}{r}\begin{array}{c}\text { Standardized } \\
\text { Regression } \\
\text { Weight }\end{array} \\
0,702\end{array}$} & \multirow{2}{*}{$\begin{array}{r}\text { Probability } \\
0,007\end{array}$} & \multirow{2}{*}{$\begin{array}{c}\text { Keterangan } \\
\text { Signifikan }\end{array}$} \\
\hline & $\begin{array}{c}\text { Endorser } \\
\text { credibility }\end{array}$ & $\leftarrow$ & $\begin{array}{c}\text { Attitude } \\
\text { homophily }\end{array}$ & & & \\
\hline $\mathrm{H} 2$ & $\begin{array}{l}\text { Parasocial } \\
\text { interaction }\end{array}$ & $\leftarrow$ & $\begin{array}{r}\text { Attitude } \\
\text { homophily }\end{array}$ & 0,222 & 0,009 & Signifikan \\
\hline $\mathrm{H} 3$ & $\begin{array}{l}\text { Parasocial } \\
\text { interaction }\end{array}$ & $\leftarrow$ & $\begin{array}{c}\text { Social } \\
\text { attractiveness }\end{array}$ & 0,034 & 0,048 & Signifikan \\
\hline $\mathrm{H} 4$ & $\begin{array}{l}\text { Parasocial } \\
\text { interaction }\end{array}$ & $\leftarrow$ & $\begin{array}{c}\text { Self } \\
\text { disclosure }\end{array}$ & 0,336 & 0,005 & Signifikan \\
\hline H5 & $\begin{array}{l}\text { Purchase } \\
\text { intention }\end{array}$ & $\leftarrow$ & $\begin{array}{l}\text { Endorser } \\
\text { credibility }\end{array}$ & 0,495 & 0,005 & Signifikan \\
\hline H6 & $\begin{array}{l}\text { Purchase } \\
\text { intention }\end{array}$ & $\leftarrow$ & $\begin{array}{l}\text { Parasocial } \\
\text { interaction }\end{array}$ & 0,12 & 0,036 & Signifikan \\
\hline
\end{tabular}

Sumber: Data diolah (2020)

Berdasarkan pengujian $\mathrm{H} 4$, variabel self-disclosure mempunyai pengaruh terhadap parasocial interaction. Pada penelitian ini dijelaskan bahwa semakin terbuka informasi dari self-disclosure dari endorser, semakin tinggi pula seseorang untuk berinteraksi.

H5 menyatakan bahwa variabel endorser credibility mempunyai pengaruh terhadap purchase intention. Pengaruh tersebut terjadi karena kredibilitas seorang endorser yang semakin tinggi mendorong seseorang untuk melakukan pembelian pada suatu produk. Menurut Sokolova dan Kefi (2019), semakin menarik, ahli, dan dapat dipercaya seorang endorser maka dapat memengaruhi 
Fresha Kharisma \& Masmira Kurniawati. Pengaruh Attitude Homophily, Social Attractiveness, Self-Disclosure, Endorser Credibility, dan Parasocial Interaction terhadap Purchase Intention

purchase intention konsumen.

Berdasarkan hasil pengujian $\mathrm{H} 6$ variabel parasocial interaction mempunyai pengaruh terhadap purchase intention. Horton dan Wohl (1956) mengatakan bahwa hubungan parasosial dipengaruhi oleh faktor ketertarikan penonton terhadap endorser.

Saat ini, perusahaan sedang bergerak ke arah komunikasi yang lebih digital untuk mempromosikan produk dan merek mereka, di mana media sosial dan pemasaran yang menggunakan endorser menjadi sesuatu hal penting untuk menentukan strategi pemasaran. Penelitian ini mempelajari bagaimana kredibilitas dan interaksi para-sosial terkait dengan niat membeli. Selain itu, hubungan tidak langsung dari sikap homophily, daya tarik fisik dan daya tarik sosial dengan niat membeli bisa bermanfaat bagi endorser yang membantu mereka mengadopsi perilaku yang lebih persuasif. Penting juga bagi pemasar untuk memahami isyarat persuasif terkait influencer yang menyajikan produk mereka. Penelitian ini memberikan gambaran tentang faktor-faktor yang memengaruhi orang untuk purchase intention. Bagi pemasar suatu produk di Indonesia hendaknya mampu memanfaatkan parasocial interaction dengan baik. Hasil penelitian menunjukkan bahwa ketika parasocial interaction memiliki pengaruh signifikan terhadap niat beli, pemasar suatu produk tidak hanya kreatif dan inovatif saja dalam menciptakan metode promosi. Endorser harus mampu membuat ikatan dengan konsumen dalam media sosial Youtube sehingga menghasilkan dorongan ke konsumen untuk membeli suatu produk hal tersebut dapat tercipta dengan berbagai cara salah satunya adalah seorang endorser harus mampu mengembangkan talenta seperti menyanyi, bermain musik, melawak, dan punya kemampuan di bidang olahraga. Cara lainnya adalah memiliki diferensiasi karakter yang menjadi ciri khas, hal tersebut akan membuat penonton yang melihat endorser tersebut menjadi ingin berinteraksi, hal itu dapat mendorong ke pembelian suatu produk yang dibawakan oleh endorser tersebut.

\section{KESIMPULAN}

Penelitian ini membuktikan bahwa attitude homophily, social attractiveness, youtuber self-disclosure, endorser credibility, dan parasocial interaction berpengaruh terhadap purchase intention. Endorser suatu produk di Indonesia hendaknya mampu memanfaatkan parasocial interaction dengan baik. Endorser harus mampu membuat ikatan dengan konsumen dalam media sosial Youtube, sehingga menghasilkan dorongan ke konsumen untuk membeli suatu produk hal tersebut dapat tercipta dengan berbagai cara salah satunya adalah dengan menggunakan komunikasi yang baik, menunjukan menjadi endorser yang ramah, berbagi informasi yang jujur tentang kondisi pribadinya dan memiliki sikap yang baik. Cara lainnya adalah memiliki diferensiasi karakter yang menjadi ciri khas. Hal tersebut akan membuat penonton yang melihat endorser tersebut menjadi ingin berinteraksi dan mendorong ke pembelian suatu produk yang dibawakan oleh endorser tersebut. Penelitian lebih lanjut disarankan melihat apakah dengan menggunakan media sosial platform lainya seperti (instagram, tik-tok dsb) akan menghasilkan reaksi secara berbeda sehingga informasi tersebut dapat bermanfaat untuk pemasar. Penelitian selanjutnya juga dapat menganalisis perbedaan karakteristik endorser dan bagaimana hal tersebut dapat sesuai dengan merek yang akan di-endorse.

\section{DAFTAR PUSTAKA}

Attahalilintarhabit.com. (2019). AHHA - Atta Halilintar Habit Official Store (https://www.ahhaofficialstore.com, diakses pada 1 Desember 2020). 
Chen, L. et al. (2016). Parasocial relationship effects on customer equity in the social media context. Journal of Business Research, 69 (9), 3795-3803. https://doi.org/10.1016/j.jbusres.2015.12.071

Cocker, H., Mardon, R. and Daunt, K.L. (2021), "Social media influencers and transgressive celebrity endorsement in consumption community contexts", European Journal of Marketing, Vol. ahead-of-print No. ahead-of-print. https://doi.org/10.1108/EJM-07-2019-0567

Djafarova, E., \& Rushworth, C. (2017). Exploring the credibility of online celebrities' Instagram profiles in influencing the purchase decisions of young female users. Computers in Human Behavior, 68, 1-7. https://doi.org/10.1016/j.chb.2016.11.009

Emarketer.com. (2017). Indonesia Internet User 2017. (https://www.emarketer.com/chart/212741/indonesia-internet-user-metrics-2017, diakses pada 1 Desember 2020).

Eyal, Keren \& Rubin, A. m. (2010). Viewer Aggression and Homophily, Identification, and Parasocial Relationships With Television Characters Viewer Aggression and Homophily, Identification, and Parasocial Relationships With Television Characters. (November 2014), 37-41. https://doi.org/10.1207/s15506878jobem4701

Forman, C, Ghose, A, \& Wiesenfeld, B (2008) Examining the relationship between reviews and sales: The role of reviewer identity disclosure in electronic markets. Information Systems Research 19(3), 291-313.

Hadijah, Siti. (2019). Inilah Alasan Mengapa Youtuber adalah Profesi yang Menjanjikan (https://www.cermati.com/artikel/inilah-alasan-mengapa-youtuber-adalah-profesi-yangmenjanjikan, diakses pada 1 Desember 2020).

Hartmann, T., \& Goldhoorn, C. (2011). Horton and Wohl revisited: Exploring viewers' experience of parasocial interaction. Journal of Communication, 61(6), 1104-1121. https://doi.org/10.1111/j.1460-2466.2011.01595.x

Kompas.com (2020). Ini 10 Youtuber Indonesia dengan Penghasilan Tertinggi (https://money.kompas.com/read/2020/06/22/050300626/ini-10-youtuber-indonesia-denganpenghasilan-tertinggi-?page $=$ all, diakses pada 1 Desember 2020)

Kurtin, Kate Szer and O'Brien, N. (2018). The Development of Parasocial Interaction Relationships on YouTube. The Journal of Social Media in Society, 7(1), 233-252.

Lee, J. E., \& Watkins, B. (2016). YouTube vloggers' influence on consumer luxury brand perceptions and intentions. Journal of Business Research, 69(12), 5753-5760. https://doi.org/10.1016/j.jbusres.2016.04.171

Lin, L. Y., \& Ching Yuh, C. Y. (2010). The influence of corporate image, relationship marketing, and trust on purchase intention: the moderating effects of word of mouth. Tourism Review, 65(3), 16-34. https://doi.org/10.1108/16605371011083503

Liu, Z. et al. (2016). Self-disclosure in Chinese micro-blogging: A social exchange theory perspective. Information and Management, 53(1), 53-63. https://doi.org/10.1016/j.im.2015.08.006

Liu, M. T., Liu, Y., \& Zhang, L. L. (2019). Vlog and brand evaluations : the influence of parasocial interaction. 31(2), 419-436. https://doi.org/10.1108/APJML-01-2018-0021

Maharani, Aulia. (2019). YouTuber Tajir, Ini 5 Bisnis Potensial Milik Atta Halilintar. 
Fresha Kharisma \& Masmira Kurniawati. Pengaruh Attitude Homophily, Social Attractiveness, Self-Disclosure, Endorser Credibility, dan Parasocial Interaction terhadap Purchase Intention

(https://www.idntimes.com/business/economy/aulia-maharani/5-bisnis-milik-atta-halilintarc1c2, diakses pada 1 Desember 2020)

Masaviru, M. (2016). Self-Disclosure: Theories and Model Review Self-Disclosure: Theories and Model Review. (May).

Mccormick, K. (2016). Journal of Retailing and Consumer Services Celebrity endorsements : In fl uence of a product-endorser match on Millennials attitudes and purchase intentions. 32, 39-45. https://doi.org/10.1016/j.jretconser.2016.05.012

Pearson, J. C., Nelson, P. E., Titsworth, S., \& Harter, L. (2011). Human Communication (4th ed). New York: The McGraw-Hill Companies, Inc.

Praditya, D. (2018). 3 Fakta Menarik tentang Perkembangan YouTube di Indonesia. TechAsia. (https://id.techinasia.com/fakta-perkembangan-youtube-di-indonesia, diakses pada 1 Desember 2020).

Ridha, A., Perdana, A. H., \& As' ad, A. (2018). Celebrity Endorser Pada Jejaring Sosialinstagram Untuk Menarik Minat Pembelian Calon Konsumen. Jurnal Economic Resource, 1(1), 86-96.

Samat Muhamad, H. haslinda dan Y. R. nerina. (2015). Endorser credibility and its influence on the attitude toward social media advertisement in Malaysia. Review of Integrative Business and Economics Research, 4(1), 144-159.

Sokolova, K., \& Kefi, H. (2019). Instagram and YouTube bloggers promote it, why should I buy? How credibility and parasocial interaction influence purchase intentions. Journal of Retailing and Consumer Services, (53)1. https://doi.org/10.1016/j.jretconser.2019.01.011

Walther, J. B., Van Der Heide, B., Kim, S. Y., Westerman, D., \& Tong, S. T. (2008). The role of friends' appearance and behavior on evaluations of individuals on facebook: Are we known by the company we keep? Human Communication Research, 34(1), 28-49. https://doi.org/10.1111/j.1468-2958.2007.00312.x

Wearesocial \& Hootsuite (2020) Digital 2020: Global Digital Overview (https://wearesocial.com/digital-2020, diakses pada 1 Desember 2020). 